\title{
Productivity is Highest in the Morning Time: An Enquiry
}

\author{
Aniket Bhalerao \\ NLP and Gestalt Master Practitioner \\ Senior Manager - The Shipping Corporation of India \\ Mumbai, India
}

\author{
Saadet Belin Atabey \\ Graduate from Bilkent University \\ Istanbul, Turkey
}

\begin{abstract}
Studying or working early in the morning is considered a more productive time in some of the articles. However, these articles may not have considered the effects of circadian rhythm. This article suggests that the emotional state of people affects the work productivity of people more than the time of day. To measure this, an online questionnaire has been sent to 111 participants through Google Forms who are between 18 and 65 years old. The Endicott Work Productivity Scale (Endicott \& Nee, 1997) and the Positive and Negative Affect Schedule (Watson et al., 1988) have been used to create the questionnaire. After performing the correlation analysis on SPSS, a weak and negative relation between positive affect and work productivity has been found. There is also a moderate and positive correlation between negative affect and work productivity. It is revealed that there are significant correlations between emotional state and work productivity, however, the reason is not known due to the nature of correlation analysis.
\end{abstract}

Keywords: Emotional State, Work Productivity, Time of the Day

\section{Introduction}

Every person wakes up at different times, studies or works at various times according to their preference. However, when is the most effective time to study and work during the day? Is it 11 p.m. at night or 7 a.m. in the morning? Is the most effective time to study the same for every person? Before evaluating the best time to study, people should look at the biological and scientific points of view of sleeping and waking up.

This Research Paper is on 'State Management' and has been authored by Aniket Bhalerao

This paper has been co-authored by Saadet Belin Atabey, an Intern part of the Global Internship Research Program (GIRP) who graduated from Bilkent University. Istanbul, Turkey.

Anil Thomas served as a Research Mentor who is a Certified NLP Master Practitioner and Gestalt Therapist. Kainaz Bharucha served as a Statistical Research Adviser who is an Intern part of the Global Internship Research Program (GIRP).This paper has been critically reviewed and proofread by Shaifila Ladhani.

We thank our Trupti Machwe (Our Editor in Chief) and Priya Pawar,( Deputy Editor in Chief) for their dedicated time and contribution towards IJNGP.

Correspondence concerning this article should be addressed to E-mail: office@ijngp
Every person has their own inner cycle of sleeping and waking up, which is also known as the circadian rhythm. Actually, the circadian cycle is more than sleeping patterns; it is affected by both darkness and light (NCI Dictionary of Cancer terms, 2021). At the same time, this inner rhythm affects the person's body temperature, hormones, cognition, mood, etc. It is also known as the body clock, because it is the cycle that people are affected by every day. This rhythm is different for every person; this difference depends on how the rhythm shifts during the day (Jun et al., 2019). The difference in circadian rhythm between people is due to genetic differences, as proven by this study by Jones et al. (2016), which demonstrates that there are 16 different variants of circadian rhythm genes that affect people's sleeping patterns. However, most people have average chronotypes, which means that people who have very extreme types of circadian rhythms are actually rare (Loria, 2017). This means that people who get up really early, like 4 to 5 a.m., or wake up really late are among those with extreme circadian rhythms. People who wake up early are known as early birds, while those who wake up later and sleep later are known as night owls. To put it simply, people who are known as early birds have their arousal peak much earlier than people who are known as night owls. 
At the peak times of arousal, people become more alert and they are better at tasks that require analytical intelligence and memory performance (Jun et al., 2019). While night owls are able to perform longer, people who have already gotten up early get tired and cannot perform analytical tasks (Jun et al., 2019). On the other hand, the creativity of these individuals (both the people who wake up early and those who wake up late) is lowest when their arousal is at its peak. On the other hand, when this arousal gets lower, their creativity increases (Jun et al., 2019). Therefore, if one wants to engage in creative tasks, then they should probably wait for the arousal to get lower. In one of the posts about the best times to study, it can be seen that the best time to study is when you have the most energy (Borgers \& Borgers, 2018). This statement is both valid and invalid at the same time, because the important thing is what kind of task the person wants to engage in and what kind of circadian rhythm they have. Another study about circadian rhythms and tasks was done by Folkard (1975). In this study, the logical reasoning of subjects was tested six different times throughout the day. The speed of subjects was getting better at times between 08.00 and 14.00. However, after $2 \mathrm{pm}$, their speed was getting worse. Moreover, the accuracy of subjects in the logical reasoning tasks was measured, which showed the results of decreasing accuracy through the day in a linear way. Therefore, it can be said that different tasks require different times for studying or working. This is also applicable to students and schoolwork. In one of the studies, Pope (2016) investigated students' productivity and efficiency in a school day in terms of their circadian rhythm and task performance. As a result, it has been found that students actually learn more in the mornings compared to evening lessons. A math lesson in the morning increased the GPA of students by 0.072 (0.006) compared to having an afternoon math class. From these examples, it can be inferred that the important factor in studying or learning a subject is the state that the person is in.

Another significant factor that determines the study time is the sleep pressure. To illustrate, while early birds have their arousal peak earlier than night owls, they actually get tired much sooner than night owls. The reason they get tired in a quicker way is the sleep pressure, which means the extent of the time that a person has been awake (Sanpera-Calbet et al., 2016). According to this, it is normal for people who get up earlier to get tired more quickly, because their sleep pressure is greater than that of people who wake up late, since more time has passed for the early birds who have woken up earlier compared to night owls who have woken up much later. Actually, the difference in their sleep patterns is not much different from each other (early birds and night owls). Both of these groups of people generally have a 2-3 hour difference between sleeping and waking up (Lack et al., 2009). In one study, the sleeping patterns of eight people who are early birds and 12 people who are night owls were studied (Lack et al., 2009). Subjective sleepiness, on the other hand, varies more in terms of hours (five to nine).This means that the significant point is when and how much the person feels alert and aroused at that time, which differs for every person because the time people use for sleeping is different due to their subjective sleepiness needs. Another study by Christina Schmidt and Philippe Peigneux was conducted on 31 people who are either extreme types of early birds or night owls (Begley, 2010). It has been found that there is a 4 hour difference between their sleeping patterns, such as while an early bird wakes up at 7 and sleeps at 11 , the night owl wakes up at 11 and sleeps at 3 in the morning. Therefore, their arousal time and circadian rhythms are different from each other, but only by 4 hours (in the extreme case). To sum up, the time people wake up or sleep does not differ very much in terms of their circadian rhythm. What does differ is how much sleep one needs in a day. This also changes the time that people feel more alert and aroused.

Everyone has a circadian rhythm and it affects people's work and study preferences, along with sleeping patterns and mood. However, is there any way to change these routines and the circadian rhythm of the body, as some might think? In an experiment, this was investigated for several months with four male subjects (Monk et al., 1989). Researchers changed these people's daily routines completely (lightness, meal times, activity times). Two of them had stretched routines, such as 26 hours, and the other two's routines were reduced to 23 hours. The subjects' alertness was measured throughout the experiment. It is found that their rhythm shows an inverted $U$ type and is controlled by the mechanisms of the sleep-wake cycle and endogenous circadian pacemaker. This demonstrates that their cycle was determined by biological forces. However, it is possible to change the state a person is in. For example, according to the author's experience, his favorite time to study is in the morning (Rampton Productivity Monday, 2018). However, it is not because he is an early bird. He wants to wake up in the morning, because it is really quiet. He says he is the only person awake at home. He has no emails or calls that he should answer, because it is really early. This means he feels more relaxed and able to focus on what he wants to do. Therefore, the important thing to study is the state that people are in. Supporting this, an experiment has been conducted on high school students (Arguedas et al., 2016). When they are able to regulate their emotions, which affects the state they are in, they are more productive and learn better compared to others, regardless of the time (morning or night). This shows that circadian rhythm and biological needs for the human body are important, but they are not the only things that 
determine one's study times. The productiveness of the work is more related to the state the person is in. Feeling more relaxed and being away from stress results in better outcomes as well as happiness. In one study, the relationship between the productivity of workers and their emotional states was investigated (Kadoya et al., 2020). There were 15 participants. Their mental status was recorded for three days, and biological forces like heart rate were controlled. They have found that happiness is correlated with productivity. This study demonstrates the importance of emotions and the state a person is in. Therefore, the best time to study is when the person feels the most happy, which will result in more productive work. Supporting this argument from another point of view, research investigates how stress and productivity are related to each other (Adaramola, 2012). On the job, stress decreases one's abilities due to both mental and emotional pressures. These pressures also result in a decrease in one's performance and productivity. Considering these points from the study, one should study at the time when he or she feels the least stressed. For example, if the stress level of one person is higher in the mornings, then they should study in the evenings or nights to increase her efficiency and productivity. Moreover, time affects people less if they are highly motivated or satisfied according to Camegie (2004) and Hadfield (1924). To illustrate, if a person feels very good as an emotional state, such as being highly motivated and satisfied, then he or she will be more productive even after ten hours of work compared to someone who has a really negative emotional state at that moment (Matuliauskaitė \& Žemeckytè, 2011). Another important aspect to note is, the emotional state of people can change because of the conditions in the workplace as well. For example, when a company does not pay as many extra checks as they have said, employees get sad and disappointed, and as a result, job satisfaction and performance suffer (Ockenfels et al, 2015). As a recent example, a research has been conducted during COVID-19 pandemic. In this research, researchers investigated employee's beliefs about remote working (Howe \& Menges, 2021). People who perceive remote working as not a learnable skill have more negative emotion about the work, therefore their productivity was significantly less compared to others (Howe \& Menges, 2021). Considering all of these examples, people should focus on having a positive emotional state rather than focusing on the benefits of waking up early. This means a person should focus on one's state of mind throughout the day. The time when one feels energetic, relaxed, and happy is the best time for them to study, because this state of mind will result in better work in terms of efficiency, productivity, and performance. Like Edison has said, "Time is the only capital that any human being has, and the only thing he can't afford to lose". By focusing on the state one is in, they can use the time more efficiently and not waste unproductive time.

Considering all of these points, it is important to be aware of one's circadian rhythm and how it affects the body, while considering the significance of sleep pressure. The arousal times show how different tasks may result in better results at different times if one needs to be more efficient in these tasks (such as being creative, the arousal should not be at its peak). However, it should also be considered that everyone has a different circadian rhythm and their need for sleep differs from each other. This demonstrates why everyone cannot work at the same time, as suggested by being a part of the 5 a.m. club. Getting up so early would not work for everyone, just like staying up at 3 am would not work for everyone either. The important thing is not deciding the time, but instead the emotional state the person has is more important. The reason is that an emotional state such as being happy, energetic, relaxed, and not stressed results in a more efficient working time. This time is also more productive, and people have higher performance compared to their lower emotional state. Therefore, knowing the time that the person feels the best is more important than being an early bird or night owl. According to these points, this article hypothesizes that the emotional state of people affects the work productivity of people more than the time of day.

\section{Method}

\section{Participants and Procedure}

In this research, the data will be obtained from adults who are working in a job or are currently studying as students. The data will be obtained from various countries, such as Turkey, the USA, the United Kingdom, and India, to have a representative sample. It is planned to gather data from at least 100 participants to have a reliable sample. Regarding the procedure of the experiment, a self-reported questionnaire will be used, which has been created in Google Forms. It will be an online questionnaire, and the data will be stored in a confidential manner. If participants want to learn more details or the results of the study, they will be sent via email. Moreover, the data from the study will be used only for research purposes, and it will not be accessible to people other than researchers and supervisors of the study. Before the study, the consent form will be given to participants, and the data will be collected only if they agree to the consent form. The questionnaire will take approximately 5 to 10 minutes.

\section{Measures}

To measure the productivity of people while they are working or studying, the Endicott Work Productivity Scale (EWPS) will be used (Endicott \& Nee, 1997). The questionnaire contains 25 items. This questionnaire has 
been chosen because it measures quality of performance, quality of work, and attendance. Items in the questionnaire are on a 5-point Likert scale, and the sum of scores is computed from 0 to 100 (from best score to worst score). Test-retest reliability on this scale is 0.9 . Cronbach's alpha is 0.92 for the community sample.

To measure the emotional state of people (whether it is positive or negative), the Positive and Negative Affect Schedule (PANAS-SF) will be used (Watson et al., 1988). The questionnaire consists of 20 items and has a 5-point Likert scale. This scale is both reliable and valid. For the positive affect on the scale, Cronbach's alpha is between .86 and .90 . For the negative affect on the scale, Cronbach's alpha is between 0.84 and 0.87

\section{Results}

This study aims to find the relationship between people's emotional states and their work productivity. The relation between these variables has been found by using the Positive and Negative Affect Schedule (PANAS-SF) and the Endicott Work Productivity Scale (EWPS).

The statistical analysis of the data has been conducted on SPSS. Two of the participants have been eliminated from the dataset since they did not satisfy the requirements. There were a total of 111 participants between 18 and 65 years old.

\section{Figure 1 Descriptive Statistics}

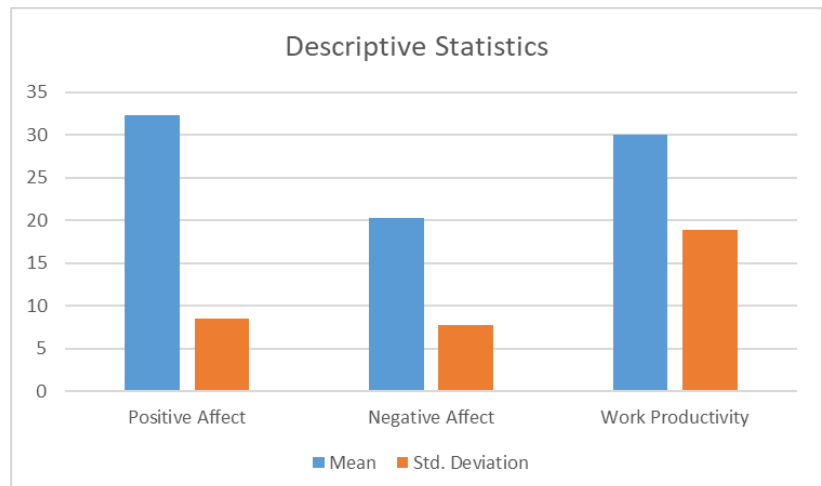

Figure 1 demonstrates the mean and standard deviation of $\mathrm{N}=$ 111. According to this table, the work productivity score is the highest mean compared to negative and positive effects. In addition, negative affect is more consistent (lowest standard deviation) compared to positive affect and work productivity.
Table 1 Correlation

\begin{tabular}{|c|c|c|c|c|}
\hline \multicolumn{5}{|c|}{ Correlations } \\
\hline & & VAR00008 & VAR00009 & VAR00010 \\
\hline \multirow[t]{3}{*}{ VAR00008 } & Pearson Correlation & 1 &,$- 242^{n}$ &,$- 204^{x}$ \\
\hline & Sig. (2-tailed) & &, 011 &, 032 \\
\hline & $\mathrm{N}$ & 111 & 111 & 111 \\
\hline \multirow[t]{3}{*}{ VAR00009 } & Pearson Correlation &,$- 242^{n}$ & 1 &, $595^{n 1}$ \\
\hline & Sig. (2-tailed) &, 011 & &, 000 \\
\hline & $\mathrm{N}$ & 111 & 111 & 111 \\
\hline \multirow[t]{3}{*}{ VAR00010 } & Pearson Correlation &,$- 204^{n}$ & $.595^{2 \pi}$ & 1 \\
\hline & Sig. (2-tailed) &, 032 &, 000 & \\
\hline & $\mathrm{N}$ & 111 & 111 & 111 \\
\hline
\end{tabular}

Note. VAR00008 means Positive Affect, VAR00009 means Negative Affect, and VAR00010 means Work Productivity.

Table 1 shows the Pearson Correlation Coefficient between positive affect, negative affect, and work productivity. According to the table, the correlation between positive affect and negative affect is weak and negative, but it is significant at the 0.05 level. The relation between positive affect and work productivity is significant at the 0.05 level, and it is a weak and negative correlation. The correlation between negative affect and work productivity is moderate and positive at the significance level of 0.01

\section{Discussion}

This study aimed to investigate the relationship between emotional state and work productivity. Before analyzing the results, it is important to know that the calculation of participants' points on the Endicott Work Productivity scale was reversed. This means that when a participant gets a score close to 100 , it means that his work productivity is really low. On the other hand, if a participant gets a score close to 0 , it means his work productivity is high. Therefore, the results related to work productivity should be interpreted in a reversed manner. This means that when work productivity is high (like in Table 1), it means that the work productivity of people is actually low.

It is important to consider the emotional state of employees when work productivity is investigated. As De Longis and Alessandri have stated, affective emotions impact the organization's efficiency and employees' behavior (2020). Moreover, job satisfaction and performance of employees are affected by their emotional states (Weiss \& Beal, 2005). Some studies found that negative emotions impact job performance negatively (Barsade \& Gibson, 2007; Kiefer, 2005). However, positive emotions have the reverse effect on employees' job performance (Wright et al., 2007). Therefore, it is important to pay attention to the work environment of employees which affects their emotional state (Edgar, 2021), and consequently, employees' emotional state may affect their work productivity. 
The results showed that there is a negative and weak correlation between positive affect and work productivity, which means when the positive affect is higher, the work productivity decreases. However, since the coding of work productivity is reversed, it actually means that when the positive effect is higher, work productivity increases. This result is also supported by the study conducted by Kadoya et al., which showed that happiness is positively correlated with productivity (2020).

The most significant result is between negative affect and work productivity. It is a positive and moderate correlation. Considering the reversed coding of work productivity, this result demonstrates that when the negative affect is high, work productivity of people decreases. This result is supported by the study by Arguedas et al. which shows the students who are able to regulate their emotions are more productive (2016). In this case, it means they are able to surpass their negative emotional state, therefore their work productivity increases. Another study which has been done by Adaramola also supports this finding (2012). According to the study, when people are stressed, their productivity decreases because of the emotional pressure. Since stress is related to negative affect, it can be said that this study supports the results of this study as well.

On the other hand, this study also supports how emotional states affect productivity, such as how studying is affected by the state. As indicated by Arguedas, high school students work more productively when they are able to regulate their emotions (2016). For example, if they are tired or grieving about something, it means that their productivity will be low. However, if they are in a happy or calm mood, their productivity will increase. This concludes that state is the important function while working or studying, not the time. Rather than focusing on studying in the morning, night, or evening, one should focus on the time when one has the most energy and positive state (Borgers \& Borgers, 2018). This is also supported by the study of Camegie which says that if a person's emotional state is positive, then he will be more productive regardless of the time of studying (2004). Moreover, it does not matter if one considers oneself as a night owl or an early bird, because emotional state is the variable that affects work productivity significantly. Therefore, the important thing is how one manages the state he or she is in, because the behavior of studying or working depends on that (Matuliauskaite \& Žemeckytè, 2011).

Considering all of these points, the hypothesis of the study is supported by the results. When the emotional state of people is positive (positive affect), their work productivity increases significantly. Furthermore, when the emotional state of people is negative (negative affect), their work productivity decreases significantly.

\section{Limitation}

This study has several limitations. Firstly, the data is collected by using Google forms, so there is a chance of bias in the results. Moreover, the study does not prove why emotional state affects work productivity; it only shows a correlation since it is not a longitudinal study. Future studies may focus on the reason behind the relationship between emotional state and work productivity to explore the topic further.

\section{Practical Implications of the Study}

Since this study has been conducted with participants from various countries, such as Turkey, India, and the United Kingdom, the results can be generalized globally. This means that employees' productivity increases when their emotional state is positive, all over the world. Employers should consider these results if they want to increase the effectiveness and productivity of their companies. Moreover, while hiring people for jobs, applicants' emotional state can be considered for a better productivity at the workplace. At the same time, students may consider their emotional state while studying to increase their productivity and have better time management in the tasks they need to do.

\section{References}

Adaramola, S. S. (2012). Job Stress and Productivity Increase. Work, 41 Suppl. 1, 2955-2958. https://doi.org/10.3233/worWOR-2012-0547-2955

Arguedas, M., Daradoumis, T., \& Xhafa, F. (2016). Analyzing the effects of emotion management on time and self-management in computer-based learning. Computers in Human Behavior, 63, 517-529. https://doi.org/10.1016/j.chb.2016.05.068

Barsade, S. G., \& Gibson, D. E. (2007). Why does affect matter in organizations? Academy of Management Perspectives, 21(1), 36-59. https://doi.org/10.5465/amp.2007.24286163

Begley, S. (2010, May 18). The brains of early birds and night owls. Newsweek. Retrieved October 26, 2021,. from https://www.newsweek.com/brains-early-birds-and-night-owls-221768.

Borgers, M., \& Borgers, M. (2018, October 27). What is the best time for studying? What is the Best Time for Studying? - - Improve Study Habits. Retrieved October 26, 2021,. https://www.improvestudyhabits.com/what-is-the-best-time-forstudying/.

Camegie, D. 2004. How to stop worrying and start living. Pocket Books. New York. 302 p.

De Longis, E., \& Alessandri, G. (2020). Temporal Dependency of Emotional States at Work and Its Relationship With Dynamic Performance. Social Psychological Bulletin, 15(2). https://doi.org/10.32872/spb.2975 
Edgar, F. (2021). Emotions and Environments: Schadenfreude at Work. Humanistic Management Journal, 1-22. https://doi.org/10.1007/s41463021-00109-X

Endicott, J., \& Nee, J. (1997). Endicott work productivity scale. PsycTESTS Dataset. https://doi.org/10.1037/t73730-000

Folkard, S. (1975). Diurnal variation in logical reasoning. British Journal of Psychology, 66(1), 1-8. https://doi.org/10.1111/j.2044$\underline{\text { 8295.1975.tb01433.x }}$

Hadfield, J. A. 1924. The Psychology of Power Macmillan, NY. 54p. doi:10.I037/10965-000

Howe, L. C., \& Menges, J. I. (2021). Remote work mindsets predict emotions and productivity in home office: A longitudinal study of knowledge workers during the Covid-19 pandemic. Human-Computer Interaction, 1-27. https://doi.org/10.1080/07370024.2021.1987238

Jones, S. E., Tyrrell, J., Wood, A. R., Beaumont, R. N., Ruth, K. S., Tuke, M. A., Yaghootkar, H., Hu, Y., Teder-Laving, M., Hayward, C., Roenneberg, T., Wilson, J. F., Del Greco, F., Hicks, A. A., Shin, C., Yun, C.- H., Lee, S. K., Metspalu, A., Byrne, E. M., ..... . Weedon, M. N. (2016). Genome-wide association analyses in 128,266 individuals identifies new morningness and sleep duration loci. PLOS Genetics, 12(8), e1006125. https://doi.org/10.1371/journal.pgen.1006125

Jun, E., McDuff, D., \& Czerwinski, M.Sefidgar, Y. S., Seo, W., Kuehn, K. S., Althoff, T., Browning, A., Riskin, E., Nurius, P. S., Dey, A. K., \& Mankoff, J. (2019). Circadian rhythms and physiological synchrony. Passively-sensed Behavioral Correlates of Discrimination Events in College Students. Proceedings of the ACM on Human-Computer Interaction, 3(CSCW)(CSCW), 1-221-29. https://doi.org/10.1145/33592162

Kadoya, Y., Khan, M. S. R., Watanapongvanich, S., \& Binnagan, P. (2020). Emotional status and productivity: Evidence from the Special Economic Zone in Laos. Sustainability, 12(4), 1544. https://doi.org/10.3390/su12041544

Kiefer, T. (2005). Feeling bad: Antecedents and consequences of negative emotions in ongoing change. Journal of Organizational Behavior, 26(8), 875-897. https://doi.org/10.1002/job.339

Lack, L., Bailey, M., Lovato, N., \& Wright, H.. (2009). Chronotype differences in circadian rhythms of temperature, melatonin, and sleepiness as measured in a modified constant routine protocol. Nature and Science of Sleep, 1, 1-8. https://doi.org/10.2147/nss.s6234

Loria, K. (2017, April 5). There's a scientific explanation for why you're a morning person or night owl - - bBut it's possible to reset your internal clock. Business Insider. Retrieved October 26, 2021, from https://www.businessinsider.com/chronotype-biological-clockcircadian-rhythm-morning-person-2017-4

Matuliauskaitė, A., \& Žemeckytè, L. (2011). Analysis of interdependencies between students' emotions, learning productivity, academic achievements and physiological parameters / Studentų emocijų, mokymosi produktyvumo, akademinių pasiekimų ir fiziologinių parametrų ryšių analizè. Mokslas: Lietuvos Ateitis, 3(2). https://doi.org/10.3846/mla.2011.032

Monk, T. H., Moline, M. L., Fookson, J. E., \& Peetz, S. M. (1989). Circadian Determinants of Subjective Alertness. Journal of Biological Rhythms, 4(4), 393-404. https://doi.org/10.1177/074873048900400401

NCI Dictionary of Cancer terms. National Cancer Institute. (n.d.). Retrieved October 15, 2021, from https://www.cancer.gov/publications/dictionaries/cancerterms/def/circadian-rhythm. National Cancer Institute.

Ockenfels A, Sliwka D, Werner P (2015) Bonus payments and reference point violations. Management Sci. 61(7):1496-1513.

Pope, N. G. (2016). How the time of day affects productivity: Evidence from school schedules. Review of Economics and Statistics, 98(1), 1-11. https://doi.org/10.1162/restREST_a_00525

RamptonProductivityMonday, J.Calendar. Retrieved October 26, 2021. https://www.calendar.com/blog/515-am-most-productive-time/. (2018, August 13). RamptonProductivityMonday, J.. Why, 5:15 a-.m. is the most productive time of My Day. Calendar. Retrieved October 26, 2021, from https://www.calendar.com/blog/515-am-most-productive-time/.

Sanpera-Calbet, I., Acuña, V., Butturini, A., Marcé, R., \& Muñoz, I. (2016). El Niño Southern Oscillation and seasonal drought drive riparian input dynamics in a Mediterranean Stream. Retrieved from http://www.jstor.org/stable/10.2307/26628408?refreqid=searchgateway. Limnology and Oceanography, 61(1), 214-226. https://doi.org/10.1002/lno.10211.

Watson, D., Clark, L. A., \& Tellegen, A. (1988). Development and validation of brief measures of positive and negative affect: The Panas scales. Journal of Personality and Social Psychology, 54(6), 1063-1070. https://doi.org/10.1037//0022-3514.54.6.1063

Weiss, H.M. and Beal, D.J. (2005) 'Reflections on affective events theory', in N. Ashkanasy, W. Zerbe, W. and C. Härtel (eds.) The effect of affect in organizational settings, Bingley: Emerald, Vol. 1, pp. 1-21.

Wright, T. A., Cropanzano, R., \& Bonett, D. G. (2007). The moderating role of employee positive wellbeing on the relation between job satisfaction and job performance. Journal of Occupational Health Psychology, 12(2), 93-104. https://doi.org/10.1037/1076-8998.12.2.93 